\title{
Mastocitosis maculopapular en un adulto
}

\section{Mastocitosis maculopapular in an adult}

\author{
M. Noelia Andrade*, Valeria E. Rossello, Virginia R. López-Gamboa, Jimena M. Nocito, \\ Andrés Guidi y Mariana B. Del Valle-Papa \\ Servicio de Dermatología, Clínica Universitaria Reina Fabiola, Córdoba, Argentina
}

\section{Resumen}

La mastocitosis maculopapular es una enfermedad con compromiso cutáneo cuyo diagnóstico puede establecerse de forma tardía debido a su baja frecuencia en adultos. En todos los casos se debe descartar compromiso sistémico. Se presenta un caso de una paciente de sexo femenino con agravamiento de las lesiones cutáneas por el uso de anestésicos desencadenantes de desgranulación mastocitaria.

Palabras clave: Mastocitosis maculopapular. Urticaria pigmentosa. Anestésicos.

\begin{abstract}
Maculopapular mastocytosis is a disease with cutaneous impact, whose diagnosis can be delayed due to its low frequency of presentation in adults, having to rule out systemic involvement. We present a case report where, after surgical interventions, the patient presented worsening of cutaneous lesions, since anesthetics, are triggers of mast cell degranulation. It is very important that the medical team can suspect this condition, for taking precautionary measures. We present a brief description of suitable drugs in this pathology according to the bibliography.
\end{abstract}

Key words: Maculopapular mastocytosis. Urticaria pigmentosa. Anesthetics.

\section{Introducción}

La mastocitosis cutánea maculopapular (MCMP) es la forma más frecuente de mastocitosis. Cuando se presenta en los adultos, el riesgo de afección sistémica aumenta y debe descartarse. Es una enfermedad rara, caracterizada por el aumento de mastocitos en la piel y sus manifestaciones clínicas son en particular secundarias a la liberación de los productos de la desgranulación mastocitaria ${ }^{1-4}$. Se presenta el caso de una paciente que se diagnosticó con MCMP luego de la exacerbación de las lesiones cutáneas, desencadenada por el estrés y los fármacos utilizados durante sus cesáreas.

\section{Caso clínico}

Paciente de sexo femenino de 37 años de edad, con antecedentes quirúrgicos de tres cesáreas. Consultó al servicio de dermatología por presentar desde la adolescencia lesiones cutáneas causantes de molestias
Disponible en internet: 06-10-2021 Med Cutan Iber Lat Am. 2021;49(Suppl 1):6-10 www.MedicinaCutanealLA.com 


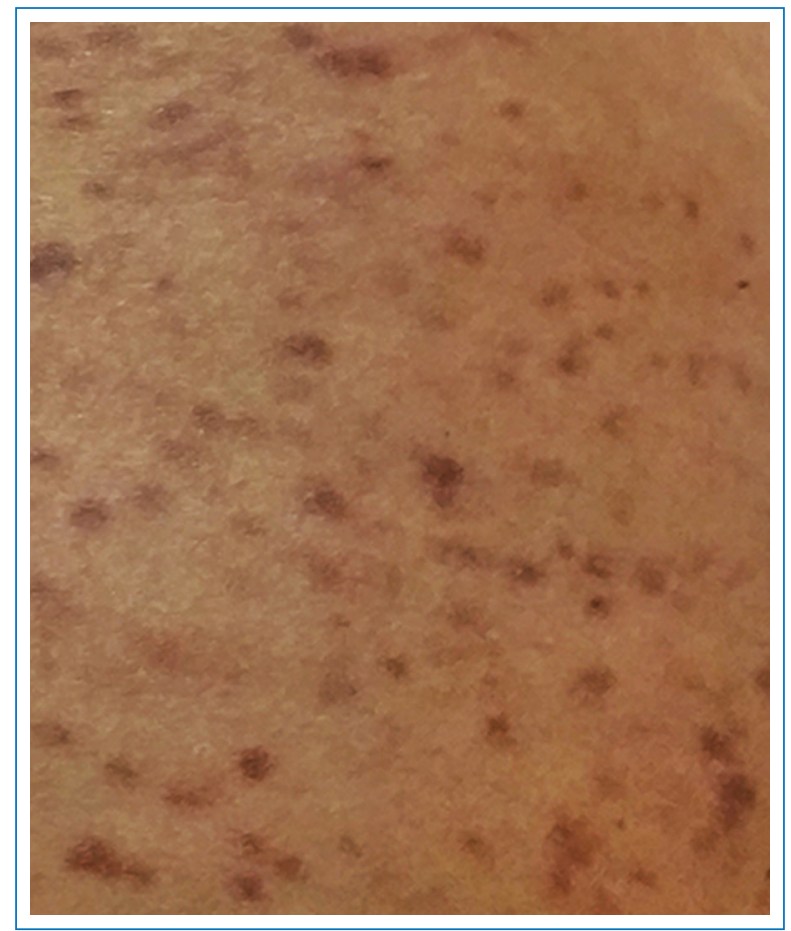

Figura 1. Lesiones observadas con mayor detalle: múltiples máculas y pápulas amarronadas.

estéticas, con edema y eritema al roce ocasionales y que luego de cada cesárea se acentuaron en número y extensión. La exploración física dermatológica reveló múltiples lesiones maculopapulares amarronadas, las de mayor tamaño de casi $1 \mathrm{~cm}$ de diámetro (Fig. 1), localizadas en cuello, tronco (Fig. 2) y raíz de miembros (Fig. 3) con urticación de las lesiones cutáneas posterior a su raspado (signo de Darier positivo). Se realizó biopsia cutánea, cuyo estudio histopatológico con tinción de hematoxilina-eosina (HE) mostró una epidermis con hiperpigmentación de la capa basal, dermis edematosa, vasos dilatados e infiltrado inflamatorio linfohistocitario con frecuentes mastocitos (Fig. 4). La tinción de azul de toluidina reveló células fusiformes con gránulos metacromáticos, consistentes con mastocitos (Fig. 4).

Al correlacionar la clínica y el estudio histopatológico se determinó el diagnóstico de mastocitosis cutánea maculopapular, previamente conocida como urticaria pigmentosa. Se solicitó triptasa sérica y ecografía abdominal, que arrojaron resultados en parámetros normales, sin afectación sistémica. Se indicó fototerapia por la extensión de las lesiones, pero ante la ausencia de síntomas al momento, la paciente decidió mantener control evolutivo. Además, se ofreció educación sobre

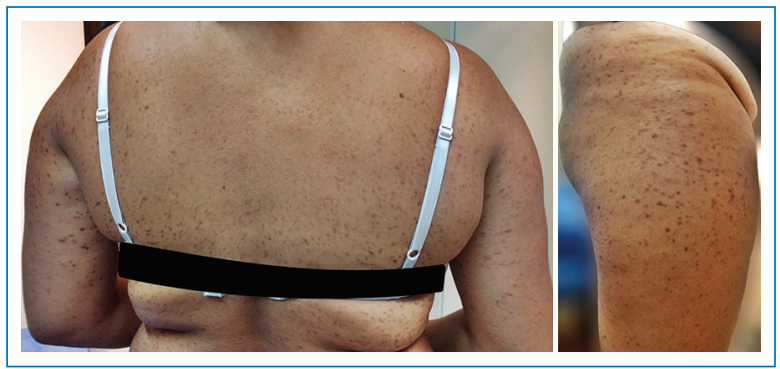

Figura 2. Máculas y pápulas amarronadas pequeñas con un diámetro máximo de $1 \mathrm{~cm}$, localizadas en el dorso y el muslo derecho.

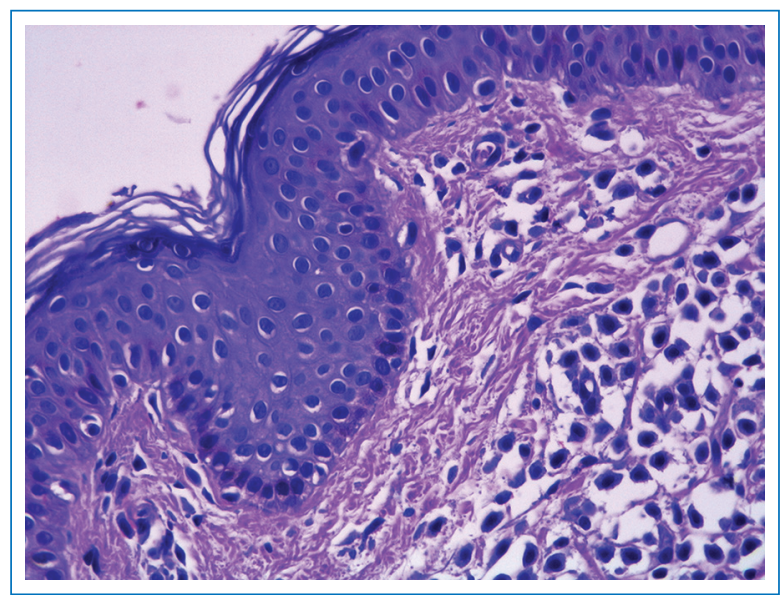

Figura 3. Biopsia con tinción H-E: mastocitos frecuentes en la dermis.

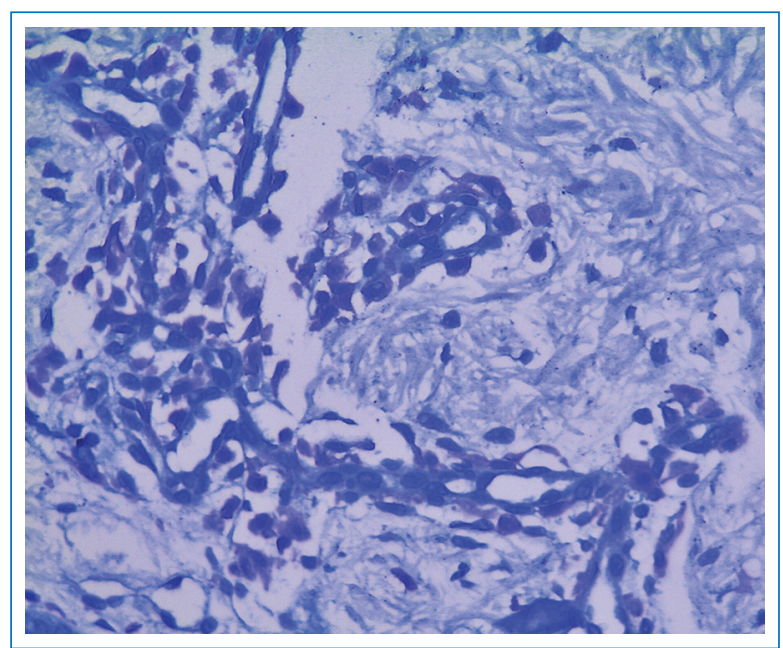

Figura 4. Biopsia con tinción azul de toluidina. Células fusiformes con gránulos metacromáticos, consistentes con mastocitos.

medidas generales para evitar desencadenantes de la desgranulación mastocitaria. 


\section{Discusión}

La mastocitosis se define como la proliferación clonal de mastocitos en distintos órganos, con más frecuencia la piel ${ }^{1-4}$, y pertenece al grupo de enfermedades raras debido a su baja prevalencia, calculada en 9 casos por 100,000 habitantes ${ }^{4,5}$. Se caracteriza por ser muy heterogénea, con múltiples variantes clínicas, y se clasifica en mastocitosis sistémica (MS), determinada por la infiltración de tejidos extracutáneos, además de la piel, y mastocitosis cutánea (MC), cuya variante clínica más frecuente es la maculopapular (MCMP) $)^{1-8}$. Ésta se presenta con distribución similar en ambos sexos y afecta a todos los grupos etarios, aunque se diagnostica más a menudo en la primera década de la vida. Cuando inicia en la adultez, la edad promedio es de 20 a 35 años ${ }^{4}$.

La etiopatogenia de la enfermedad se relaciona con las mutaciones activadoras del protooncogén c-kit. La más encontrada se halla en el exón 17, en el codón 816 (D816V) e induce la proliferación autónoma desregulada de los mastocitos con su acumulación en los tejidos. También se han identificado alteraciones inmunofenotípicas en los mastocitos, como la expresión de CD25 y CD302,4,7,8.

En clínica se observan máculas y pápulas que suelen ser pequeñas, redondas y monomorfas, eritematosas y amarronadas, variables en número y tamaño y con signo de Darier positivo ${ }^{3}$. La localización habitual es el tronco y casi nunca se afecta la piel del rostro ${ }^{3,8}$. Aunque la mastocitosis puramente cutánea puede ocasionar síntomas sistémicos como respuesta a diversos mediadores inflamatorios, el diagnóstico de MS se correlaciona con un nivel elevado de triptasa sérica (valor normal $<20 \mu \mathrm{g} / \mathrm{L}$ ) e infiltración mastocitaria en médula ósea ${ }^{3}$. En la mastocitosis avanzada también pueden infiltrarse otros tejidos y como consecuencia presentar linfadenopatías, hepatoesplenomegalia, disfunción hepática, malabsorción, citopenias y lesiones osteolíticas ${ }^{2,7}$.

El diagnóstico dermatológico definitivo de mastocitosis cutánea se define por la triada de lesión cutánea típica, confirmación histopatológica y ausencia de afectación sistémica. En la histología se observan infiltrados focales de mastocitos (más de 15 identificables con azul de toluidina o Giemsa) en la dermis ${ }^{6}$. Los diagnósticos diferenciales se deben establecer con sífilis secundaria, enfermedades pigmentarias de la piel como pigmentación macular eruptiva idiopática, dermatosis cenicienta, liquen pigmentario, pitiriasis liquenoide crónica, formas reactivas de mastocitosis como
Tabla 1. Desencadenantes de liberación de mediadores mastocitarios

\begin{tabular}{|l|l|}
\hline $\begin{array}{l}\text { Agentes } \\
\text { físicos }\end{array}$ & Calor \\
\hline & Frío \\
\hline Presión \\
\hline Roce de lesiones cutáneas \\
\hline emocionales & Fiebre \\
\hline $\begin{array}{l}\text { Drogas y } \\
\text { fármacos }\end{array}$ & $\begin{array}{l}\text { Ácido acetilsalicílico y antiinflamatorios no } \\
\text { esteroideos (AlNE) }\end{array}$ \\
\hline Alcohol \\
\hline Renenos & $\begin{array}{l}\text { Relajantes musculares e inductores empleados } \\
\text { en la anestesia general }\end{array}$ \\
\hline & Anestésicos locales \\
\hline Contrastes yodados \\
\hline
\end{tabular}

reacciones alérgicas mediadas por $\lg \mathrm{E}$, urticaria autoinmunitaria crónica, farmacodermias y algunas enfermedades inflamatorias que afecten a los mastocitos como la dermatitis atópica².

La fisiopatología de las manifestaciones clínicas se explica por la liberación de mediadores mastocitarios, como histamina, prostaglandinas, heparina y citocinas $^{4}$, que inducen respuestas locales como prurito y rubor, y sistémicas al liberarse al torrente sanguíneo, como hipotensión, cefalea o choque anafiláctico ${ }^{2}$. Los cuadros anafilácticos con riesgo vital se reconocen hasta en $22 \%$ de los pacientes adultos y se pueden correlacionar con los valores de triptasa sérica ${ }^{2,4}$. Los desencadenantes de la desgranulación mastocitaria se describen en la Tabla 14,7-9. Dentro del grupo de fármacos sistémicos, en la Tabla 2 se especifican aquellos seguros en el contexto quirúrgico en un paciente con MCMP. Los anestésicos locales tipo éster están contraindicados, por lo que se puede optar por los de tipo amida $^{10}$.

No se dispone en la actualidad de un tratamiento curativo para esta enfermedad, pero se pueden utilizar diferentes combinaciones de fármacos según sean las manifestaciones clínicas del paciente. Los fármacos tópicos son opciones para las lesiones cutáneas localizadas, entre ellos el cromoglicato de sodio, aunque no 
Tabla 2. Farmacología perioperatoria en paciente con mastocitosis

\begin{tabular}{|c|c|c|c|}
\hline & $\begin{array}{l}\text { Tiempo en relación con } \\
\text { la intervención quirúrgica }\end{array}$ & Fármacos recomendados & Fármacos no recomendados \\
\hline \multicolumn{4}{|l|}{ Día previo } \\
\hline $\begin{array}{l}\text { Valoración por los servicios de anestesia } \\
\text { y hematología }\end{array}$ & 14 días previos & & \\
\hline Prueba cutánea seleccionada & 7 días previos & & \\
\hline \multicolumn{4}{|l|}{ Día de la operación } \\
\hline $\begin{array}{l}\text { Continuar con medicación habitual para } \\
\text { mastocitosis }\end{array}$ & Por la mañana & & \\
\hline Administración de benzodiacepinas & 1 hora previa & Midazolam & \\
\hline \multirow{2}{*}{$\begin{array}{l}\text { Administración de antihistamínicos } \\
\mathrm{H}_{1} \text { y } \mathrm{H}_{2}\end{array}$} & \multirow[t]{2}{*}{30 minutos previos } & Ranitidina* & \\
\hline & & Clorfenilhidramina * & \\
\hline Administración de esteroides & 30 minutos previos & Metilprednisolona & \\
\hline \multicolumn{4}{|l|}{ Durante la operación } \\
\hline \multicolumn{4}{|l|}{ Mantener la temperatura corporal } \\
\hline \multirow[t]{2}{*}{ Relajantes musculares } & & Rocuronio* & \multirow[t]{2}{*}{ Succinilcolina } \\
\hline & & Remifentanilo* & \\
\hline \multirow{9}{*}{$\begin{array}{l}\text { Anestésicos con agentes inhalados } 0 \\
\text { intratecales }\end{array}$} & & Intratecales: & Tiopental \\
\hline & & Bupivacaína & Morfina \\
\hline & & Lidocaína* & Procamida \\
\hline & & Diazepam & Fentanilo (controversial) \\
\hline & & Ketamina & Metilparabeno \\
\hline & & Generales: & \\
\hline & & Fentanilo* & \\
\hline & & Propofol* & \\
\hline & & Etomidato* & \\
\hline \multirow[t]{3}{*}{ Colapso vascular } & \multirow[t]{3}{*}{ Según sea necesario } & Epinefrina & \\
\hline & & Corticoides & \\
\hline & & Antihistamínicos & \\
\hline \multicolumn{4}{|l|}{ Posoperatorio } \\
\hline Esteroides/ antihistamínicos adicionales & \multirow{3}{*}{$\begin{array}{l}\text { Por 24-48 h posteriores, } \\
\text { en pacientes sintomáticos }\end{array}$} & & \\
\hline \multirow[t]{2}{*}{ Analgesia } & & \multirow[t]{2}{*}{ Fentanilo* } & Meperidina \\
\hline & & & Morfina \\
\hline
\end{tabular}

* Permitido en el embarazo, categoría B.

se conoce exactamente el mecanismo de acción, y los corticoides. Ambos fármacos están disponibles por vía oral, que al igual que los antihistamínicos $\mathrm{H}_{1} \circ \mathrm{H}_{2}$, son útiles en casos sistémicos ${ }^{1,7,8}$. Además de su actividad antihistamínica, estos últimos interfieren con la liberación de mediadores mastocitarios, sobre todo los de segunda generación ${ }^{1}$. Otra opción es el fármaco antileucotrienos montelukast, y en casos graves resistentes 
se requieren corticoides sistémicos junto con epinefrina en caso de anafilaxia. Se ha experimentado con éxito el tratamiento antiinmunoglobulina $\mathrm{E}$ con omalizumab, pero continúa en estudio ${ }^{1,7}$. La fototerapia puede ser útil en casos con lesiones cutáneas extensas, ya que reduce el número de mastocitos en la piel y en ocasiones se puede obtener la atenuación de la hiperpigmentación ${ }^{2,7}$. Es de suma importancia la prevención de la desgranulación mastocitaria mediante la educación activa a los pacientes, su entorno familiar y el personal de salud ${ }^{1,7,8}$. El tratamiento debe ser multidisciplinario e individualizado, según sean la gravedad y el tipo de manifestaciones clínicas ${ }^{1}$.

\section{Conclusiones}

La sospecha clínica es indispensable para el diagnóstico temprano de la MCMP, lo cual mejora la calidad de vida de los pacientes al recibir asesoría para la prevención de los factores desencadenantes y opciones terapéuticas para los síntomas.

En caso de ser operaciones programadas, se recomienda realizar premedicación con antihistamínicos $\mathrm{H}_{1}$ y $\mathrm{H}_{2}, \mathrm{y}$ administrar benzodiacepinas para reducir el grado de ansiedad y estrés. Los inductores anestésicos propofol, ketamina, benzodiacepinas y etomidato son fármacos seguros; el etomidato es de elección en pacientes de alto riesgo anafiláctico. El rocuronio es una opción plausible si se necesitan relajantes musculares y, de los analgésicos opioides, el fentanilo es una buena opción para el dolor posquirúrgico $0^{5,10}$.

A pesar de que la paciente obtuvo un diagnóstico tardío, no repercutió sistémicamente en su organismo y se mantiene en control evolutivo.

\section{Financiamiento}

Los autores no recibieron financiamiento alguno para la realización del manuscrito.

\section{Conflicto de intereses}

Los autores no presentan ningún conflicto de intereses.

\section{Responsabilidades éticas}

Protección de personas y animales. Los autores declaran que para esta investigación no se han realizado experimentos en seres humanos ni en animales.

Confidencialidad de los datos. Los autores declaran que han seguido los protocolos de su centro de trabajo sobre la publicación de datos de pacientes.

Derecho a la privacidad y consentimiento informado. Los autores han obtenido el consentimiento informado de los pacientes y/o sujetos referidos en el artículo. Este documento obra en poder del autor de correspondencia.

\section{Bibliografía}

1. Azaña JM, Torrelob A, Matitoc A. Actualización en mastocitosis. Parte 2: categorías, pronóstico y tratamiento. Actas Dermosifiliogr. 2016;107(1):15-22.

2. Cookson HA, Grattan CB. An update on mast cell disorders. CME Immunology and Allergy. 2016;16 (6): 580-3.

3. Hartmann K, Escribano L, Grattan C, Brockow K, Carter MC, Álvarez-Twose I, et al. Cutaneous manifestations in patients with mastocytosis: consensus report of the European Competence Network on Mastocytosis; the American Academy of Allergy, Asthma \& Immunology; and the European Academy of Allergology and Clinical Immunology. J Allergy Clin Immunol. 2016 Jan;137 (1):35-45.

4. Johnson MR, Verstovsek S, Jorgensen JL, Manshouri T, Luthra L, Jones DM, et al. Utility of the World Health Organization classification criteria for the diagnosis of systemic mastocytosis in bone marrow. Modern Pathology. 2009;22:50-7.

5. Ochoa-Chaar Cl, Bell RL, Duffy TP, Duffy AJ. Guidelines for safe surgery in patients with systemic mastocytosis. Am Surg. 2009 Jan;75(1):74-80.

6. Azaña JM, Torrelob A, Matitoc A. Actualización en mastocitosis. Parte 1 fisiopatología, clínica y diagnóstico. Actas Dermosifiliogr. 2016;107(1):5-14.

7. Álvarez-Twose I, Matito A, Sánchez-Muñoz L, Morgado JM, Escribano L. Management of adult mastocytosis. Expert Opinion on Orphan Drugs. 2014;2(4):321-36.

8. De la Hoz B, González de Olano D, Álvarez I, Sánchez L, Núñez R, Sánchez I, et al. Guías clínicas para el diagnóstico, tratamiento y seguimiento de las mastocitosis. An Sist Sanit Navar. 2008;31(1):11-32.

9. Villeneuve V, Kaufman I, Weeks S, Deschamps A. Obstetrical and pediatric anesthesia anesthetic management of a labouring parturient with urticaria pigmentosa. Can J Anesth. 2006;53(4):380-4.

10. Longás-Valién J, Martínez-Ubieto J, Muñoz-Rodríguez L, Girón-Mombiela JA, Gonzalo-Pellicer I, Pardillos-Calatayud C. Manejo anestésico en la mastocitosis. Rev Esp Anestesiol Reanim. 2005; 52:105-8. 